\title{
Short Communication ATTITUDINAL PREFERENCES FOR SOCIO-CULTURAL PRACTICES IN CHAKMA TRIBE
}

\author{
Md. Kamal Hossain* \\ Department of Psychology \\ Cantonment Public College, Saidpur, Nilphamari, Bangladesh \\ *Correspondence (email: kamal_cpscs@yahoo.com)
}

\begin{abstract}
mú rok: Młel YwU c w WPZ w

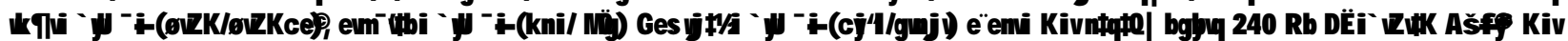

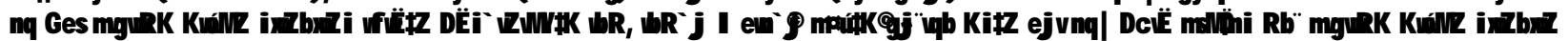

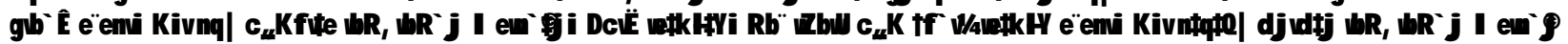

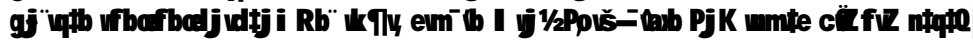

Key words: Socio-cultural practices, Intergroup relations, cultural identity, Chakma tribe.

Ethno-linguistic theory takes into account individual's cognitive representations of the socio-cultural practices (SCPs) operating in interethnic context. Giles et al. (1977) compiled a list of ethno-linguistic vitality variables and recognized the socio-cultural forces as the dynamic element in the growth and maintenance of an ethnic community. It is argued that the more vitality a particular group is said to have, the more likely it will survive as an active collective entity in interethnic competitions. Hence ethno-linguistic minorities having little or no group vitality in terms of SCPs would eventually cease to exist as distinctive collectivities (Bourhis, 1979). In the context of these theoretical perspectives, an empirical investigation was conducted to measure the attitudinal preferences for SCPs of Chakma people in Chittagong Hill Tracts of Bangladesh.

Chakmas are mostly Buddhists and represent the largest and the best known group in Chittagong Hill Tracts. They no longer speak a Kuki-Chin language of their ancestors, as a result, their language became an aberrant form of Chittagong dialect. It may be properly classified as a separate language of Indo-Aryan origin, which has heavy admixture of other elements. It is written with the Burmese script (Samad 1984). Badaruddin (1984) observed that Chakmas have a separate identity in respect of their customs and culture. They are the enlightened, educated and culturally advanced compared to other tribes of the country.

It is now established that the Chakmas have their distinct origin and anthropological history of their own race (Hunter 1876; Dewan 1969). Hence, it is important to note that the SCPs of these tribal people would play a vital role in their interethnic relationships. The present study focuses on attitudinal preferences of this tribe as related to education, residence and gender in Chittagong Hill Tracts, where it was hypothesized that (i) undergraduate respondents would express more preference for their cultural practices as compared to graduate respondents; (ii) rural respondents would express higher preference for their cultural practices as compared to their urban counterparts; and (iii) male respondents would express more preference for their cultural practices as compared to female respondents.

Sample: The study used a stratified random sample composed of 240 Chakma students, equally divided into graduates and undergraduates. Equal number of males and females were included in the sample. The respondents came from urban and rural residential background in equal number. Thus the study involved a $2 \times 2 \times 2$ factorial design consisting of 30 respondents in each cell. The age of the respondents ranged between 17 and 24 years.

Instrument: A measure of SCPs, that evaluated the attitudinal preferences in Chakma tribe, was used for collecting data. The measure included 10 statements concerning SCPs, such as (1) manner of living, (2) customs and traditions, (3) marriage system, (4) manner of speech, (5) dress style, (6) religious practices, (7) celebrations of festivals, (8) system of divorce, (9) remarriage of widow and (10) dowry system. The respondents were required to evaluate these items on three frames of references such as self, own-group and out-group. For determining the reliability of the measure, the split-half reliability was computed with odd and even numbers and the Spearman's correlation co-efficient (r) was found 0.53. When Spearman-Brown Prophecy formula was applied, however, the correlation was found to be 0.69 , indicating a high reliability of the test. 
Procedures: The measure of SCPs was administered on 240 respondents individually. They subjects were personally contacted in their hostels, residence as well as in college campuses, invariably through Chakma agents. They were asked to express their judgments on three evaluative levels mentioned above. In order to get three evaluative judgments, the measure of SCPs was administered separately on three occasions. Each respondent therefore was required to evaluate each category independent of each other with a gap of one week. Initially the respondents were very much suspicious about the motive of the survey. But they were assured that their answers would be kept secret and would be used only for research purposes. They were requested to answer all questions as honestly as possible. Each respondent took hardly half an hour on average to fill in each questionnaire.

Table 1. Mean scores and significant mean differences between graduate/undergraduate, urban/ rural and male/female respondents against the self-, own-group and out-group evaluations on the scores of socio-cultural practices (SCPs) in Chakma students in Chittagong Hill Tracts, Bangladesh.

\begin{tabular}{|c|c|c|c|c|c|c|}
\hline Parameters & Graduate & Undergraduate & Urban & Rural & Male & Female \\
\hline Education level & 45.30 (self) & & & & & \\
\hline Graduate & $\begin{array}{c}45.45 \text { (own) } \\
42.40 \text { (out) }\end{array}$ & & & & & \\
\hline Undergraduate & & $\begin{array}{c}47.25 \text { (self) } \\
46.49 \text { (own) } \\
40.04 \text { (out) }\end{array}$ & & & & \\
\hline \multicolumn{7}{|l|}{$\begin{array}{l}\text { Residential } \\
\text { background }\end{array}$} \\
\hline Urban & $\begin{array}{l}\text { 46.15a (self) } \\
41.78 \mathrm{a} \text { (out) }\end{array}$ & $\begin{array}{l}\text { 47.17a (self) } \\
\text { 42.05b (out) }\end{array}$ & $\begin{array}{c}46.66 \text { (self) } \\
45.45 \text { (own) } \\
41.92 \text { (out) }\end{array}$ & & $\begin{array}{c}\text { Graduate } \\
\text { 41.33b (out) } \\
\text { undergraduate } \\
\text { 42.67a (out) }\end{array}$ & $\begin{array}{c}\text { Graduate } \\
\text { 42.23a (out) } \\
\text { undergraduate } \\
\text { 41.43b (out) }\end{array}$ \\
\hline Rural & $\begin{array}{l}\text { 44.45b (self) } \\
38.30 \mathrm{c} \text { (out) }\end{array}$ & $\begin{array}{l}\text { 47.33a (self) } \\
\text { 42.75b (out) }\end{array}$ & & $\begin{array}{c}45.89 \text { (self) } \\
46.49 \text { (own) } \\
40.52 \text { (out) }\end{array}$ & $\begin{array}{c}\text { Graduate } \\
\text { 39.67c (out) } \\
\text { undergraduate } \\
\text { 42.80a (out) }\end{array}$ & $\begin{array}{c}\text { Graduate } \\
\text { 36.93d (out) } \\
\text { undergraduate } \\
\text { 42.70a (out) }\end{array}$ \\
\hline \multicolumn{7}{|l|}{ Gender } \\
\hline Male & & & 42.00a (out) & 41.23a (out) & $\begin{array}{c}41.62 \text { (own) } \\
41.62 \text { (out) }\end{array}$ & \\
\hline Female & & & 41.83a (out) & 39.82b (out) & & $\begin{array}{c}40.42 \text { (own) } \\
40.82 \text { (out) } \\
\end{array}$ \\
\hline
\end{tabular}

Dissimilar scripts differ significantly by Newman-Keuls tests $(\mathrm{P}<0.05)$.

Scoring: All the respondents were asked to express their preferences for SCPs on a 5-point scale ranging from totally true (marked 5) to totally false (marked 1). The maximum possible score was 50 and the minimum 10 . A score on and above 30 was regarded as positive preference for the SCPs. High scores indicated acceptance of own-group SCPs while low scores suggested acceptance of change in the own-group SCPs. Mean differences in SCPs were subjected to Newman-Keuls tests to interpret the results. In addition, the scores of SCPs were subjected to a $2 \times 2 \times 2$ factorial ANOVA representing 2 levels of education (graduate/ undergraduate), 2 levels of residence (urban/rural) and 2 levels of gender (male/female). The ANOVA was computed for the three frames of references i.e. self, own-group and out-group separately.

Self-evaluation: Regardless of residence and gender, undergraduate Chakma respondents $(M=47.25)$ expressed significantly more preference for their cultural practices as compared to graduate Chakma respondents $(\mathrm{M}=45.30)$ for self-evaluation (Table 1). It was also found that regardless of education and gender, the urban Chakma respondents $(M=46.66)$ expressed significantly higher preference for their cultural practices as compared to their counterpart rural respondents $(\mathrm{M}=45.89)$ for selfevaluation. The main effects of self-evaluation on education $(\mathrm{F}=25.32, \mathrm{df}=1 / 232, \mathrm{P}<0.01)$ and residence $(\mathrm{F}=3.91, \mathrm{df}=1 / 232, \mathrm{P}<0.05)$ were statistically significant (Table 2). The interaction effect of education and residence is significant at 0.05 . An inspection of mean scores (Table 1) showed that graduate Chakma respondents of urban origin $(\mathrm{M}=46.15)$ expressed significantly more preference for their cultural practices as compared to the respondents of rural origin $(\mathrm{M}=44.45)$ of the same educational level. Again, undergraduate urban $(M=47.17)$ and rural $(M=47.33)$ Chakma respondents expressed significantly more preference for 
their cultural practices as compared to graduate respondents of rural origin ( $\mathrm{M}=44.45)$.

Table 2. Effects of education, residential background and gender on the scores of socio-cultural practices (SCPs) against the self, own-group and out-group evaluations in Chakma students in Chittagong Hill Tracts, Bangladesh.

\begin{tabular}{|c|c|c|c|c|}
\hline $\begin{array}{c}\text { Sources of } \\
\text { variance }\end{array}$ & Df & $\begin{array}{c}\text { F-values } \\
\text { for } \\
\text { self } \\
\text { evaluations }\end{array}$ & $\begin{array}{c}\text { F-values } \\
\text { for own- } \\
\text { group } \\
\text { evaluations }\end{array}$ & $\begin{array}{c}\text { F-values } \\
\text { for out- } \\
\text { groups } \\
\text { evaluations }\end{array}$ \\
\hline $\begin{array}{c}\text { Educational } \\
\text { level (A) }\end{array}$ & $1 / 232$ & $25.32^{* *}$ & $63.21^{* * *}$ & $57.54^{* * *}$ \\
\hline $\begin{array}{c}\text { Residential } \\
\text { background (B) }\end{array}$ & $1 / 232$ & $3.91^{*}$ & $11.52^{*}$ & $20.04^{* *}$ \\
\hline Gender (C) & $1 / 232$ & $3.42 \mathrm{~ns}$ & $8.13^{*}$ & $6.48^{*}$ \\
\hline $\mathrm{A} \times \mathrm{B}$ & $1 / 232$ & $5.80^{*}$ & $1.63 \mathrm{~ns}$ & $45.26^{* * *}$ \\
\hline $\mathrm{A} \times \mathrm{C}$ & $1 / 232$ & $0.001 \mathrm{~ns}$ & $2.92 \mathrm{~ns}$ & $0.16 \mathrm{~ns}$ \\
\hline $\mathrm{B} \times \mathrm{C}$ & $1 / 232$ & $2.14 \mathrm{~ns}$ & $0.26 \mathrm{~ns}$ & $4.04^{*}$ \\
\hline $\mathrm{A} \times \mathrm{B} \times \mathrm{C}$ & $1 / 232$ & $1.07 \mathrm{~ns}$ & $1.01 \mathrm{~ns}$ & $14.69^{* *}$ \\
\hline $\mathrm{Df}=\mathrm{d} g \mathrm{r}$
\end{tabular}

$\mathrm{Df}=$ degrees of freedom; ns $=$ not significant; $*=\mathrm{P}<0.05 ; * *=$ $\mathrm{P}<0.01 ; * * *=\mathrm{P}<0.00$.

Own-group evaluation: The results on own-group evaluation showed that the main effects for education ( $F=63.21, \quad \mathrm{df}=1 / 232, \quad \mathrm{P}<0.01)$, residence $\quad(\mathrm{F}=11.52$, $\mathrm{df}=1 / 232, \quad \mathrm{P}<0.01)$ and gender $(\mathrm{F}=8.13, \quad \mathrm{df}=1 / 232$, $\mathrm{P}<0.05$ ) were all statistically significant (Table 2). Regardless of residence and gender, the undergraduate Chakma respondents ( $M=46.49)$ expressed significantly higher preference for their cultural practices as compared to their counterpart graduate respondents $(M=45.45)$ for own-group evaluation (Table 1). Similarly, It was found that regardless of education and gender, Chakma respondents of rural origin $(\mathrm{M}=46.49)$ expressed significantly higher preference for their SCPs as compared to the Chakma respondents of urban origin $(M=45.45)$ for own-group evaluation. Again, it was found that regardless of education and residence, male Chakma respondents ( $M=41.62)$ expressed significantly higher preference for their SCPs than their counterpart female respondents $(\mathrm{M}=40.42)$ for own-group evaluation. Results on own-group evaluation, however, revealed no interaction effects.

Out-group evaluation: The results on out-group evaluation, on the other hand, showed that the main effects for education ( $\mathrm{F}=57.54, \mathrm{df}=1 / 232, \mathrm{P}<0.01)$, residence $(\mathrm{F}=20.04, \mathrm{df}=1 / 232, \mathrm{P}<0.01)$ and gender $(\mathrm{F}=6.48, \mathrm{df}=1 / 232, \mathrm{P}<0.05)$ were statistically significant (Table 2). The results suggested that irrespective of residence and gender, graduate Chakma respondents $(M=42.40)$ expressed significantly higher preference for their SCPs of out-group as compared to undergraduate Chakma respondents $(\mathrm{M}=40.04)$. Results also showed that irrespective of education and gender, urban Chakma respondents $(\mathrm{M}=41.92)$ expressed significantly higher preference for socio-cultural practices for out-group as compared to rural Chakma respondents ( $M=40.52)$. Similarly, regardless of education and residence, Chakma male respondents ( $M=41.62)$ expressed higher preference for SCPs for out-group as compared to female Chakma respondents ( $\mathrm{M}=40.82)$. The interaction effect of education and residence was found significant at 0.05 level. An inspection of mean scores (Table 1) showed that graduate Chakma respondents of urban origin $(\mathrm{M}=41.78)$ expressed significantly higher preference for SCPs for out-group as compared to graduate respondents of rural origin $(\mathrm{M}=38.30)$. But urban undergraduate respondents $(M=42.05)$ expressed significantly higher preference for SCPs of out-group as compared to urban graduate respondents $(\mathrm{M}=41.78)$. Again, rural undergraduate respondents $(M=42.75)$ expressed higher preference for SCPs of out-group as compared to rural graduate respondents $(\mathrm{M}=38.30)$.

Again, the interaction effect of residence and gender was significant at 0.05 level. An inspection of mean differences showed that urban male respondents $(M=42.00)$, urban female respondents $(\mathrm{M}=41.83)$ and rural male respondents $(\mathrm{M}=41.23)$ expressed significantly higher preference for SCPs of the out-group as compared to rural female respondents $(M=39.82)$. The interaction effect of education, residence and gender was significant at 0.01 level. An inspection of the mean scores showed that graduate female respondents of urban origin $(\mathrm{M}=42.23)$ expressed higher preference for SCPs of out-group as compared to graduate male respondents of urban origin $(\mathrm{M}=41.33)$. Again, graduate male respondents of rural origin ( $M=39.67)$ expressed significantly higher preference for SCPs of the out-group as compared to graduate female respondents of rural origin $(\mathrm{M}=36.93)$. While undergraduate male respondents of urban origin $(\mathrm{M}=42.67)$ expressed higher preference for SCPs of outgroup as compared to their counterparts of undergraduate female respondents of urban origin ( $\mathrm{M}=41.43)$.

The present results revealed three important findings. (1) Regardless of residence and gender, undergraduate Chakma respondents $(\mathrm{M}=46.49)$ showed more preference for their own-group cultural practices as compared to the graduate Chakma respondents $(\mathrm{M}=45.45)$. This finding supports the theoretical paradigm of intergroup relations. While it is recognized that the bulk of the problems of intergroup relations may arise due to social, economic and political causes, the manifestations and roots of ethnic hostility fall clearly in the realm of SCPs. Tajfel's (1978) social identity theory has recognized this aspect of social and cultural practices as marker of ethnicity. According to him, the social climate of group differentials in terms of 
culture moulds the way in which the young children come to think of themselves and their group as different from the out-group. On the basis of this theoretical arguments, it might be said that undergraduate Chakma respondents have accepted socio-cultural practices of their own as marker of social identity in greater extent than the graduate Chakma respondents. (2) Regardless of education and gender, Chakma respondents of rural origin ( $\mathrm{M}=46.49)$ expressed higher preference for their own SCPs as compared to Chakma respondents of urban origin ( $M=45.45)$. This finding is consistent with previous findings conducted in different parts of the world (Fishbein and Ajzen 1974; Nandey and Kakar 1980; Ajzen 1987; Devellis et al. 1990). In the present situation, it may be argued that the rural population of Chakma tribe has more affinity with their own cultural practices. As they are comparatively less educated than the Chakma of urban background, they are more conservative, more prejudicial and more ethnic in their inter-group behaviour. Perhaps these social variables might be responsible for making the rural Chakma people to be more affiliated with their culture than the urban Chakma people. (3) Regardless of education and residence, male Chakma respondents $(\mathrm{M}=41.62$, $\mathrm{M}=41.62$ ) expressed higher preferences for SCPs of own-group and out-group as compared to female Chakma respondents ( $M=40.42, M=40.82)$. This finding can be explained in the perspectives of belief congruence theory of Rokeach et al. (1960), who devised race-belief experimental paradigm and showed that belief in terms of SCPs was more important than race in maintaining inter-group relations. Thus belief congruence is seen as a property in interpersonal relations. The male Chakma people are more affiliated to their SCPs as carrier of cultures. This is the crux of the situation that led male Chakma population to show more adherences to their own cultural practices as a marker of tribal identity.

The overall results indicated that undergraduate, rural and male Chakmas expressed more preferences for cultural practices compared to those for their counterparts. The graduate and urban Chakmas had frequent contacts with the out-group than the undergraduate and rural Chakmas, and as such they are less prejudicial. The study helps us to penetrate into the hidden treasure of Chakma customs and traditions. It needs to recognize that the tribal people possess a tradition and great heritage of their national history. It is only the recognition of this aspect of Chakma tribe that can provide a linkage for mutual understanding, cooperation and friendship. It is the obligation of the dominant group of a country to provide umbrella supports to this disadvantageous group for its proper growth and to save their cultural heritage. We should show liberal attitudes for accepting the existence of tribal culture within their fold so that they could protect their rights and traditional practices. However, the study suggests further research using larger samples and appropriate sampling techniques to come up with more reliable findings.

\section{References}

Ajzen I. 1987. Attitudes, traits and actions: Disposional prediction of behaviour in personality and social psychology. In: Advances in Experimental Social Psychology (ed. Berkowitz L.), pp. 1-63. Academic Press, New York.

Badruddin M. 1984. The Chakmas and Their Customary Laws. In: Tribal Cultures in Bangladesh (ed. Qureshi, MS.), pp. 274-286. Institute of Bangladesh Studies, Rajshahi University.

Bourhis RY. 1979. Language and Ethnic Interaction. In: Language and Ethnic Relations (eds. Giles $\mathrm{H}$ and Jacques B St.). Pergamon, Oxford, UK.

Devellis BM, Blalock SJ and Sandler RS. 1990, Predicting participation in cancer screening: The role of perceived behavioural control. J. Appl. Social Psychol. 20: 639-660.

Dewan BM. 1969. Chakma Jatir Itibritta, Rangamati. 114 pp.

Fishbein M and Ajzen I. 1974. Attitudes toward objects and predictors of single and multiple behavioural criteria. Psychol. Rev. 81: 319-342.

Giles H, Bourhis RY and Taylor DM. 1977. Towards a Theory of Language in Ethnic Group Relations. In: Language, Ethnicity and Intergroup Relations (ed. H. Giles H.). Academic Press, London.

Hunter WW. 1876. A Statistical Account of Bengal. London, 45 pp.

Nandy A and Kakar S .1980. Culture and Personality. In A Survey of Research in Psychology (ed. Pareek U.) Part I, pp. 1971-1976, Popular Prakashan, Bombay, Indian Council of Social Science Research.

Rokeach M, Smith PW and Evans RI. 1960. Two Kinds of Prejudice or one. In: The Open and Closed Mind (ed. Rokeach M.). Basic Books, New York.

Samad AG. 1984 Notes on our Tribal population. In: Tribal Cultures in Bangladesh (ed. Qureshi MS.), pp. 53-60. Institute of Bangladesh Studies, Rajshahi University.

Tajfel H. 1978 (ed.) Differentiation between social groups. Studies in the Social Psychology of Intergroup Relations. Academic press, London.

Manuscript received on 4 May 2010 and revised on 8 December 2011 